\title{
DEVELOPMENT AND VALIDATION OF GRAPHITIC CARBON ANALYSIS OF GRAPHITE ORE SAMPLES
}

Tamara Mariana Guilherme Ribeiro ' Paulo Roberto Gomes Brandão ${ }^{2}$

\begin{abstract}
The evaluation of a graphite deposit inevitably involves the determination of graphitic carbon content in the ore. This work consisted in a detailed assessment of the method for the determination of this element in graphite ore samples using a process, which involves acid leaching, calcination, combustion and infrared detection stages. From the data obtained, it was possible to understand the importance of each one of these operations and to identify the optimal conditions for the analysis with a significant turnaround time reduction. The optimized methodology was then validated with certified reference materials according to selected parameters. Inter-laboratory tests were carried out with ore samples from Almenara/Brazil graphite deposit. The data demonstrate that the method is very appropriate for determining the graphitic carbon content in ore samples, generating reliable and high quality results.
\end{abstract}

Keywords: Graphite; Graphitic carbon; Analysis; Method.

\section{INTRODUCTION}

Graphite corresponds to the more stable natural allotropic form of carbon under normal pressure and temperature conditions. Its structure is formed by hexagonal carbon atoms arrays linked by covalent bonds [I]. The arrays overlap each other in sheets connected together by Van der Waals type forces.

The difference between the intensities of the forces in both directions is responsible for the anisotropic properties of the material [2]. Furthermore, due to the weak bonding between planes, the graphite crystals are very susceptible to disorder in this direction, which gives the material its softness and lubricity characteristics [3].

Carbon in the graphite ores may have different origins, whether organic, carbonates and/or graphitic (or elementary). For industrial applications, the most important species is the graphitic carbon, which has the crystalline structure responsible for the unique physical-chemical properties of the material. Therefore, in the evaluation of a graphite deposit, it is essential to have knowledge of graphitic carbon content in the ore.

Most common procedures for determining the graphitic carbon content in ore the samples consist of leaching the material with hydrochloric acid solution to remove carbonates. Then the material is heated to eliminate organic carbon by conversion to $\mathrm{CO}_{2}$. The product obtained in the end of this process contains only the graphitic carbon which can be measured either by combustion and infrared detection in a specific analyzer [4-7] or by gravimetric method [8].
The present study was set to investigate each step of the methodology for graphitic carbon determination and identify the optimum analysis conditions. The improved methodology was validated using certified reference materials and inter-laboratory tests were performed with ore samples to certify the quality of the results.

\section{EXPERIMENTAL PROCEDURE}

\section{I Methodology Development}

The first part of this work consisted of an evaluation of the steps involved in the current method of graphitic carbon determination used in Almenara Graphite Project. A detailed study about the influence of test conditions on the final results was carried out in order to improve the analytical procedure. The main objective was to reduce the eight hours turnaround time for the analysis.

To measure the effect of changes in tests conditions on the analytical results, this development was done using the certified reference materials (CRM) produced by Geostats Pty Ltd, as showed in Table I. These graphite ore standards have the expected graphitic carbon levels for the laboratory routine.

The original methodology for determination of graphitic carbon in ore samples comprises the following steps:

'Centro de Pesquisa e Desenvolvimento, Magnesita Refratários S.A., Contagem, MG, Brazil. E-mail: tamara.ribeiro@magnesita.com

${ }^{2}$ Escola de Engenharia, Universidade Federal de Minas Gerais, Belo Horizonte, MG, Brazil. 
Table I. Certificate reference materials

\begin{tabular}{cccccc}
\hline \multirow{2}{*}{ CRM } & \multicolumn{2}{c}{ Total carbon (\%) } & & \multicolumn{2}{c}{ Graphitic carbon (\%) } \\
\cline { 2 - 3 } \cline { 5 - 6 } & Certified value & Standard deviation & & Certified value & Standard deviation \\
\hline GGC-06 & 8.16 & 0.24 & 0.68 & 0.38 \\
GGC-08 & 1.03 & 0.27 & & 0.39 & 0.06 \\
GGC-09 & 2.95 & 0.18 & & 2.41 & 0.27 \\
GGC-10 & 5.22 & & & 4.79 & 0.29 \\
\hline
\end{tabular}

a. weighing the sample as received on the ceramic combustion boat;

b. drying the sample in an oven at $108{ }^{\circ} \mathrm{C}$ for I hour to remove moisture;

c. I st leaching with $\mathrm{HCl} \mathrm{I}: \mathrm{I}$, using enough solution to fill the combustion boat;

d. removing the solution from the combustion boat by washing and filtration;

e. $2^{\text {nd }}$ leaching with $\mathrm{HCl} \mathrm{I}: \mathrm{I}$, using enough solution to fill the combustion boat;

f. removing the solution from the combustion boat by washing and filtration;

g. calcination of the sample in an electric oven at $400^{\circ} \mathrm{C}$ for two hours;

h. cooling the sample at room temperature;

i. analysis of residual material in carbon analyzer LECO SC-632.

The stages were evaluated individually through analysis conducted with seven replicates. Grubbs test [9] was applied to certify that there were no outliers in the results.

\section{I.I Sample drying}

At this stage, the influence of sample moisture in the results was evaluated. Dried and non dried samples were analyzed and the values obtained for graphitic carbon were compared.

\subsubsection{Acid leaching}

The ore leaching with hydrochloric acid is a key stage in graphitic carbon analysis process, since carbonates are eliminated at this point. The number of stages needed to ensure the effectiveness of this operation (one, two or three) was studied.

\subsubsection{Removing acid solution}

The original analysis procedure requires removing of hydrochloric acid of the combustion boat by vacuum filtration. In this case, the replacement of the filtering operation by the evaporation of the acid at $100{ }^{\circ} \mathrm{C}$ on a hot plate was investigated. The main advantage of this change would be the reduction in analysis time, because the heating process is much faster than filtering.

\section{I.4 Calcination}

The influence of the oven temperature and calcination time on the graphitic carbon results was also studied. Initially the work was done only with the CRM GGC-09 sample. The following conditions were evaluated: time ( $\mathrm{l} h$ and $2 \mathrm{~h}$ ) and temperatures $\left(400{ }^{\circ} \mathrm{C}, 450{ }^{\circ} \mathrm{C}, 500{ }^{\circ} \mathrm{C}, 550{ }^{\circ} \mathrm{C}\right.$ and $600^{\circ} \mathrm{C}$ ). The best time and temperatures pairs were tested for other standards.

\section{I.5 Equipment calibration curve}

The last evaluated step was the analysis of the samples in the LECO SC-632. The reference materials were analyzed with two different calibration curves, one being constructed with the graphite ore standard GGC-06 and another with the standard LECO 50I-025, recommended by the equipment supplier, which is metallic and has carbon content equal to $3.35 \%$

\subsection{Method Validation}

The validation of an analytical method is the confirmation that a specific requirement for a specific use is fulfilled [ 10$]$. This should include, when applicable: selectivity, linearity, linear working range, detection limit, quantification limit, recovery, accuracy, precision and robustness [II]. The parameters evaluated in this work are listed in the items that follow.

\subsection{Linearity and linear range}

The linearity is the ability of a method to demonstrate that its results are directly proportional to the concentration of the analyte in the sample, within the linear working range. Five samples with known graphitic carbon content were used to calculate these parameters. They were produced from diluting the CRM GGC-06 with the silica standard BCS-313/2, produced by Bureau of Analyzed Samples. The concentration levels were $0.5 \%, 2.5 \%, 4.5 \%, 6.5 \%$ and $8.0 \%$. Each of these samples was analyzed seven times and the average results were compared with the values expected by linear regression analysis. 


\subsubsection{Accuracy and precision}

To check the precision and accuracy of the proposed methodology, seven replicates of the GGC-09 standard were analyzed.

The precision refers to the degree of agreement among repeated measurements of the same characteristic in the same sample collected in the closest possible conditions. This was assessed by the Horrat test, which is the ratio of the method standard deviation and the Horwitz relative standard deviation (Equation I). Precision is approved when Horrat parameter is less or equal 2 [12].

$R S D_{\text {Horvitz }}=2^{(1-0,5 \log C)}$

where $\mathrm{C}$ is the analyte concentration in mass percentage.

Accuracy indicates how close the measured and the true values are. Its evaluation was performed using the relative error (Equation 2). If this parameter is between $\pm 5.0 \%$ then the method has a good level o accuracy.

$R E=\left(X_{l a b}-X_{v}\right) / X_{v}$

where $X_{\text {lab }}$ is the average concentration of the seven replicates and $X_{v}$ is the certified value.

\subsubsection{Quantification and detection limits}

To determine the detection and quantification limits, seven replicates of blank samples were analyzed according to the optimized methodology. These blanks were, actually, the ceramic combustion boat with the burn accelerator COM-CAT LECO.

The detection limit corresponds to the smallest value of analyte concentration that can be detected by the method. Its value is estimated from the average concentration of blanks plus three times the standard deviation for the replicates.

The quantification limit corresponds to the lowest amount of analyte concentration which can be quantified by the method. Its value is estimated from the average concentration of blanks plus ten times the standard deviation obtained for the replicates.

\subsection{Inter-laboratory Tests}

After the method development and validation, an inter-laboratory study was conducted with 170 graphite drilling samples from Almenara/Brazil graphite deposit. It is a flake graphite deposit, located in the Minas-Bahia graphite province, with an average grade of $2.2 \%$ graphitic carbon $[13,14]$.

Two commercial laboratories participated in these trials. The relative differences between the results obtained by them were calculated as shown in Equation 3. These results were graphically compared to the standard deviation calculated from the Horwitz equation. If the relative difference (RD) is smaller than the Horwitz standard deviation, then the data are comparable.

$$
R D=\left[\left(X_{\text {MRSA }}-X_{i}\right) /\left(\left(X_{\text {MRSA }}+X_{i}\right) / 2\right)\right] * 100
$$

where $\mathrm{X}_{\text {MRSA }}$ is the result in Magnesita's laboratory and $\mathrm{X}_{\mathrm{i}}$ is the result in the commercial laboratory (I or 2).

\section{RESULTS AND DISCUSSION}

\section{I Methodology Development}

The first evaluated parameter was the influence of samples moisture on the final results. As can be seen in Figure I, the relative differences between the certificate value and analysis results for each condition (dried and non dried samples) were very close, showing that there was no influence of drying on the final result. As the tests were carried out with very low moisture content standards, it was decided to keep this operation in the procedure.

The results of tests carried out with one, two and three hydrochloric acid leaching stages are shown in Table 2. There is no relevant difference between the results obtained with two or three leaching stages.

The relative differences between the expected values and the results for the single leaching samples are much higher than that observed for the other conditions, indicating that it is insufficient to remove all carbonates from the material. In fact, the larger relative differences were obtained for the samples containing more non graphitic carbon: GGC-08 and GGC-09. This shows that it is not possible to reduce the number of leaching stages from two to one.

The investigation about the best way to remove the hydrochloric acid from the combustion boats showed that there is no significant difference between the results obtained in filtering/washing and evaporation routes (Figure 2). This means that is possible to replace the one operation by the other without compromising the quality of the analysis. This is a very important conclusion, since filtering and washing is the most time consuming step in graphitic carbon determination method. This process, which is done in two stages (one after each leaching step), takes around four hours to be complete, while each evaporation

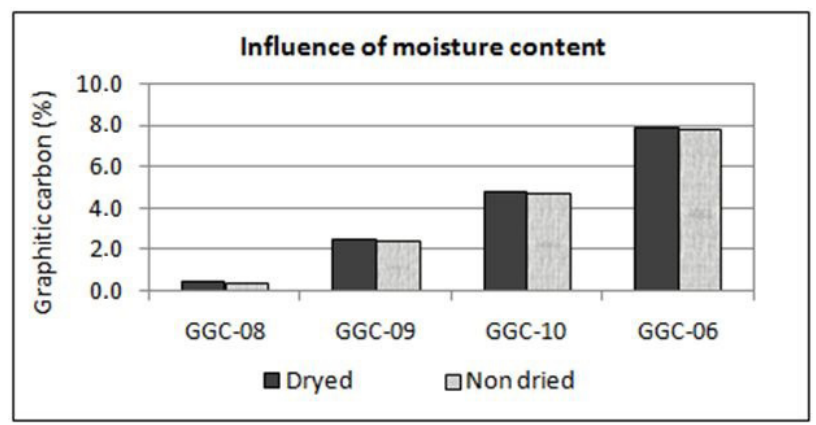

Figure I. Influence of moisture content in graphitic carbon results. 
Table 2. Influence of number of leaching stages in graphitic carbon results

\begin{tabular}{|c|c|c|c|c|c|c|c|}
\hline \multirow[b]{2}{*}{ CRM } & \multirow{2}{*}{$\begin{array}{c}\text { Certified } \\
\text { value (\%) }\end{array}$} & \multicolumn{2}{|c|}{ C graph - One stage (\%) } & \multicolumn{2}{|c|}{ C graph - Two stages (\%) } & \multicolumn{2}{|c|}{ C graph - Three stages (\%) } \\
\hline & & $\begin{array}{c}\text { Analytical } \\
\text { result }\end{array}$ & $\begin{array}{c}\text { Relative } \\
\text { difference }\end{array}$ & $\begin{array}{c}\text { Analytical } \\
\text { result }\end{array}$ & $\begin{array}{c}\text { Relative } \\
\text { difference }\end{array}$ & $\begin{array}{c}\text { Analytical } \\
\text { result }\end{array}$ & $\begin{array}{c}\text { Relative } \\
\text { difference }\end{array}$ \\
\hline GGC-08 & 0.39 & 0.61 & 56.4 & 0.41 & 4.0 & 0.40 & 3.7 \\
\hline GGC-09 & 2.41 & 2.89 & 19.9 & 2.51 & 4.2 & 2.50 & 3.9 \\
\hline GGC-10 & 4.79 & 5.19 & 8.4 & 4.71 & -1.7 & 4.76 & -0.7 \\
\hline GGC-06 & 7.68 & 8.79 & 14.5 & 7.77 & 1.2 & 7.80 & 1.6 \\
\hline
\end{tabular}

step lasts only 10 minutes. This is a key factor for reduction of analysis turnaround time and increased productivity in the laboratory.

Figure 3 shows the results of calcination time and temperature tests for CRM GGC-09. The data indicate that the graphitic carbon content tends to decrease with increasing of both parameters and the temperature seems to have more influence on the results. The values obtained for $550{ }^{\circ} \mathrm{C}$ and $600^{\circ} \mathrm{C}$ are very low, indicating loss of graphitic carbon. Results for $400^{\circ} \mathrm{C}, 450{ }^{\circ} \mathrm{C}$ and $500^{\circ} \mathrm{C}$ (in one or two hours) are within the acceptable range calculated considering the CRM standard deviation.

Considering these results and seeking to optimize the analysis time, it was decided to perform new tests at $400^{\circ} \mathrm{C}$ and $500^{\circ} \mathrm{C}$ during one hour for the four certified reference materials. As showed in Figure 4, the values obtained in both conditions are very similar and within the standard deviation for the reference materials. This indicates that is possible to reduce the calcination time from two to one hour while maintaining the oven temperature at $400{ }^{\circ} \mathrm{C}$.

The last evaluated parameter was the equipment calibration curve. The results, shown in Table 3, indicate that the values tend to fit better in the GGC-06 curve. This may be occurring due to two different factors. The first and most important is the matrix effect. GGC-06 is a mineral ore standard, very similar to the samples that are being analyzed, while LECO $50 \mathrm{I}-024$ is a metallic reference material which may contain components that can affect the instrumental response. The second is that LECO $50 \mathrm{I}-024$ has only 3.35\% of graphitic carbon, which means that all results above this value were obtained by extrapolation in the curve, thereby increasing the analytical error.

After completing the evaluation about the impact of modifying the analysis conditions, an optimized procedure for graphitic carbon determination was proposed as follows:

a. weighing the sample as received on the ceramic combustion boat;

b. drying the sample in an oven at $108^{\circ} \mathrm{C}$ for I hour to remove moisture;

c. Ist leaching with $\mathrm{HCl} \mathrm{I}: \mathrm{I}$, using enough solution to fill the combustion boat;

d. removing the solution from the combustion boat by evaporation at $100^{\circ} \mathrm{C}$;

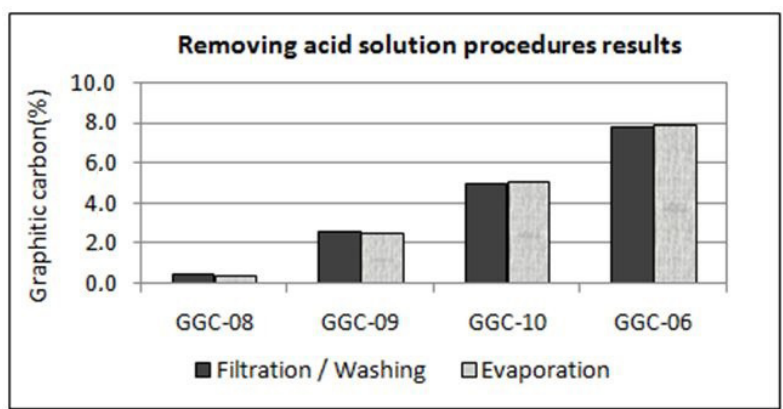

Figure 2. Influence of $\mathrm{HCl}$ filtration/washing and evaporation in graphitic carbon results.

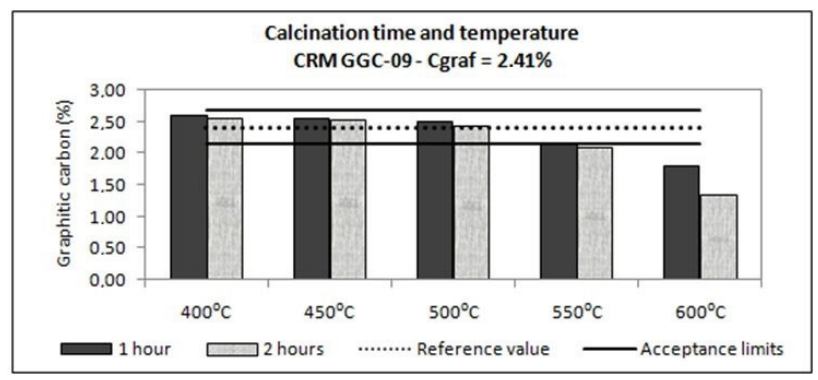

Figure 3. Influence of calcination time and temperature in graphitic carbon results for CRM GGC-09

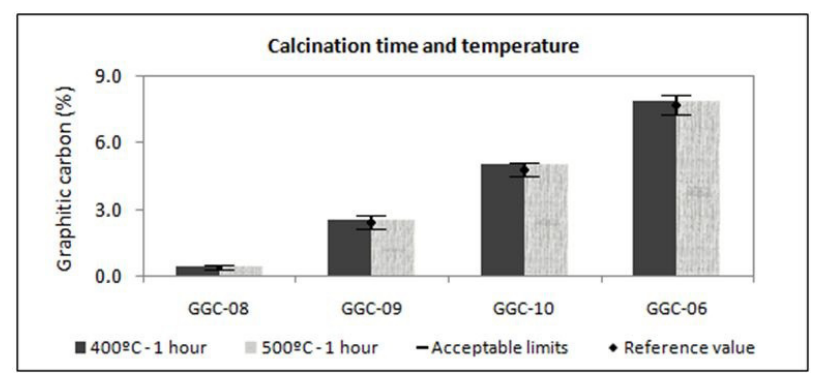

Figure 4. Influence of calcination time and temperature in graphitic carbon results.

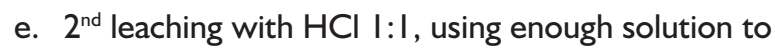
fill the combustion boat;

f. removing the solution from the combustion boat by evaporation at $100^{\circ} \mathrm{C}$;

g. calcination of the sample in an electric oven at $400^{\circ} \mathrm{C}$ for one hour;

h. cooling the sample at room temperature; 
Table 3. Influence of calibration curve in graphitic carbon results

\begin{tabular}{|c|c|c|c|c|c|}
\hline \multirow{3}{*}{ CRM } & \multirow{3}{*}{ Certified value (\%) } & \multicolumn{2}{|c|}{ C graph } & \multirow{2}{*}{\multicolumn{2}{|c|}{$\begin{array}{c}\text { C graph } \\
\text { LECO 50 I-024 Curve (\%) }\end{array}$}} \\
\hline & & \multicolumn{2}{|c|}{ GGC-06 Curve (\%) } & & \\
\hline & & Analytical result & Relative difference & Analytical result & Relative difference \\
\hline GGC-08 & 0.39 & 0.39 & -0.1 & 0.47 & 20.9 \\
\hline GGC-09 & $2.4 I$ & 2.36 & -1.9 & 2.44 & I.I \\
\hline GGC-10 & 4.79 & 4.78 & -0.2 & 5.13 & 7.0 \\
\hline GGC-06 & 7.68 & 7.78 & 1.3 & 8.14 & 5.9 \\
\hline
\end{tabular}

i. analysis of the residual material in the LECO SC-632 carbon analyzer, using the GGC-06 calibration curve.

With this new procedure the analysis turnaround time has been reduced from eight to four hours with no losses in the quality of the results produced by the laboratory.

\subsection{Method Validation}

Once the analytical procedure was set, the method validation was initiated. The first two parameters evaluated were linearity and linear working range, as shown in Figure 5. The linearity was verified by the linear regression obtained by comparing the measured and expected concentrations for the analyte. The determination coefficient $\left(R^{2}\right)$ is greater than 0.99 , which means that the method is suitable for analyzes in the defined working range $(0.5 \%$ to $8.0 \%)$.

Precision and accuracy were evaluated from seven replicate analyses of the GGC-09 standard. The results are presented in Table 4.

The method has good repeatability since the result of Horrat test is less than two. Moreover, the relative standard deviation was only $0.33 \%$, indicating that it presents good precision.

The relative error was $0.53 \%$, an extremely low value, which indicates good accuracy. The results were very close to the certificate value.

The detection and quantification limits calculated from seven replicates of blank samples were $0.02 \%$ and $0.07 \%$, respectively.

\subsection{Inter-laboratory Tests}

The inter-laboratory tests were performed with I 70 drilling samples collected in Almenara deposit with graphitic carbon grade ranging from $0.01 \%$ up to $26.0 \%$, of which $85 \%$ presented content of this element within the validated working range. It should be emphasized that this set of samples contains ore and waste samples, which explains the wide variation observed in graphitic carbon levels.

The graphs in Figures 6 and 7 show that the relative differences calculated between the analytical results of the internal laboratory (MRSA) and the commercial laboratories "A" and "B" are within the limits established by the Horwitz equation. This indicates that the data are reproducible and can be compared.

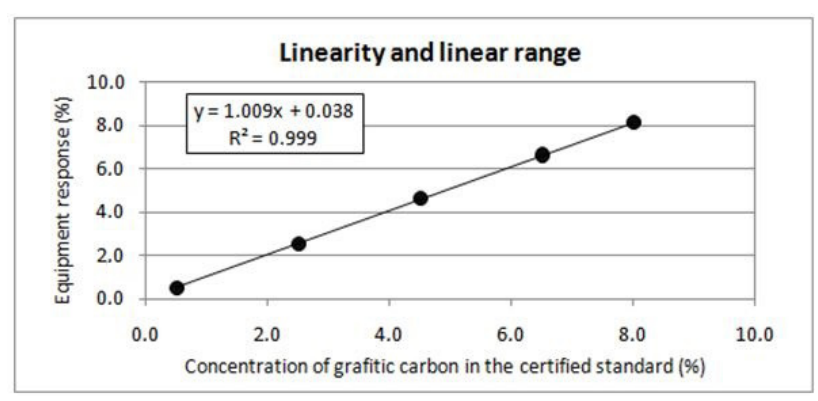

Figure 5. Linearity and linear working range for graphitic carbon optimized method.

Table 4. Precision and accuracy

\begin{tabular}{cccc}
\hline \multirow{2}{*}{$\begin{array}{c}\text { Analytical } \\
\text { results }\end{array}$} & Mean & 2.93 & $\%$ \\
\cline { 2 - 4 } & Standard deviation (SD) & 0.01 & $\%$ \\
\hline \multirow{3}{*}{ Precision } & Certified value & 2.95 & $\%$ \\
\cline { 2 - 4 } & Relative standard deviation (RSD) & 0.33 & $\%$ \\
\cline { 2 - 4 } & Horwitz relative standard deviation RSD & 3.40 & $\%$ \\
\cline { 2 - 4 } & Horrat & 0.10 & \\
\hline Accuracy & Relative error & 0.53 & $\%$ \\
\hline
\end{tabular}

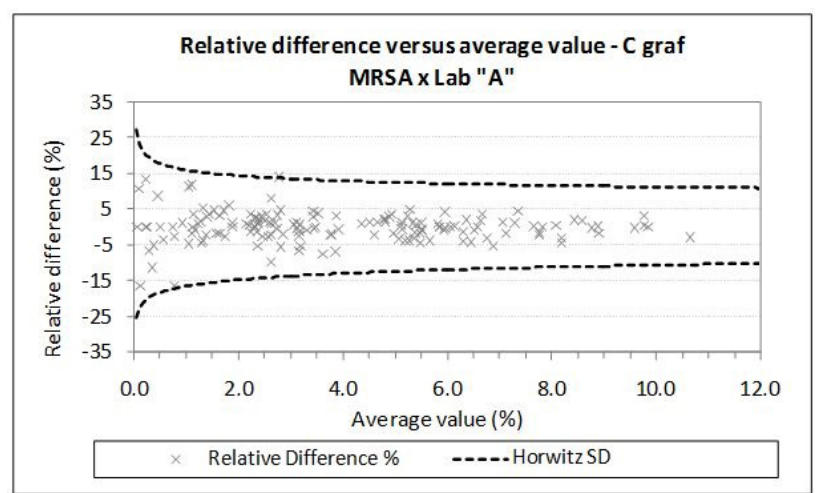

Figure 6. Comparison between results of graphitic carbon reported by MRSA and commercial laboratory "A" - Horwitz analysis.

It is an important conclusion since it shows that the results achieved through the optimized methodology proposed in this paper have good agreement with those obtained by methods established and practiced by commercial laboratories. 


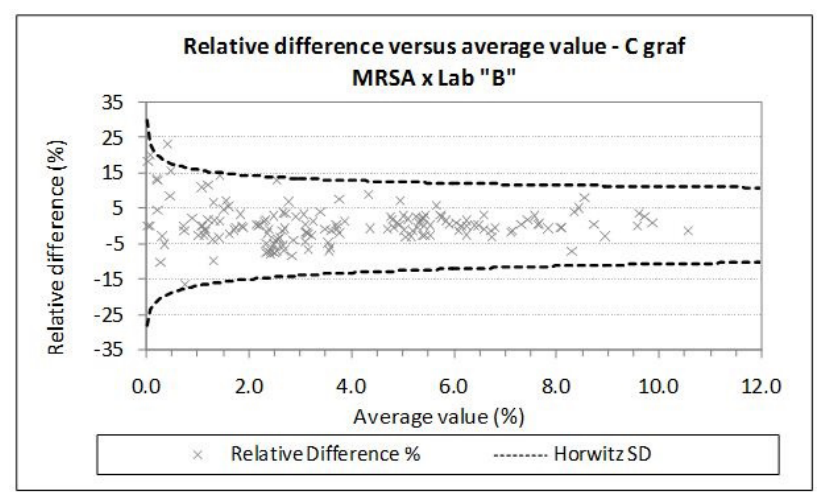

Figure 7. Comparison between results of graphitic carbon reported by MRSA and commercial laboratory "B" - Horwitz analysis.

\section{CONCLUSIONS}

The present study presents an optimized methodology for graphitic carbon analysis in ore samples. It is based in classic methods and involves several stages of treatment for removing non graphitic carbon, besides combustion and infrared detection. However, with some improvements, it was possible to reduce the turnaround analysis time from eight to four hours, without compromising the quality of the analysis.

The main proposed changes were the replacement of the washing and filtration stages for removing the hydrochloric acid of the combustion boat by the evaporation process and reduction in calcination time. The other standard conditions should not be changed since it may affect the results.

Filtering and washing is the most time consuming step in the original methodology, taking about four hours to be completed. When this operation is substituted by the evaporation process this time drops to only 20 minutes, enhancing the laboratory capacity.
Calcination is another critical stage and can not be performed in temperatures above $550^{\circ} \mathrm{C}$, since higher this parameters is, the higher is the probability of losing the graphitic carbon by oxidation. In this case it was possible to reduce the calcination time from two to one hour while maintaining the oven temperature at $400{ }^{\circ} \mathrm{C}$.

The study also showed that at least two hydrochloric acid leaching stages must be performed to ensure complete removal of carbonates from the system prior to combustion and infrared detection. If these species remain on the samples, they will not be distinguished from graphitic carbon, providing wrong results.

After defining these new conditions, validation studies and inter-laboratory trials were performed with geology samples from Almenara graphite deposit to check the method performance.

The results obtained with the optimized method were consistent with the observed in commercial laboratories. The analysis also presented good levels of precision and accuracy. This indicates that the method has the characteristics required to obtain quality results, and therefore is suitable for determining the graphitic carbon content in mineral samples.

\section{Acknowledgements}

The authors are thankfull to Alexandre Leonardo Pereira, Hélio da Silva Pedrosa, Maria Aparecida Gomes da Silva, Simone Jaqueline dos Santos Lopes and Jéssica Rosa Lulho for their contribution with this work. The authors are also grateful to the following institutions and offices: the Federal University of Minas Gerais (UFMG), the Post-Graduate Program in Metallurgical, Materials and Mining Engineering (PPGEM) and to CAPES/PROEX. The co-author P.R.G. Brandão also acknowledges CNPq for a research grant.

\section{REFERENCES}

I King RJ. Minerals explained: graphite. Geology Today. 2006;22(2):7I-77.

2 Bonnissel N, Luo L, Tonfeur D. Compacted exfoliated natural graphite as heat conduction medium. Carbon. 200I;39:2I5I-2I6I.

3 Villanueva AEL. Produção de novos materiais carbonáceos por altas pressões. Porto Alegre: Instituto de Física, Universidade Federal do Rio Grande do Sul; 2003. 78 p.

4 Saikkonen RJ, Rautiainen IA. Determination of total and non-carbonate carbon In rock samples by a method using infrared absorption. Bulletin of the Geological Society of Finland. 1990;62(part 2): 149-I56.

5 Terashima S. A direct method for the determination of carbonate and non-carbonate carbon in geological materials by infrared spectrometry. Analytica Chimica Acta. 1979; I08: I I 3- I I8.

6 Krom MD, Berner RA. A rapid method for the determination of organic and carbonate carbon in geological samples. Journal of Sedimentary Research. 1983;53(2):660-663.

7 Eccles D, Nicholls S, Hough R. 2015 indicate and inferred graphite creek resource estimate at the graphite creek property, Alaska, United States. Canada; 20I5. Technical Report.

8 Bernier S, Chartier D, Burga E. Technical Report for the Lochaber Graphite Project, Quebec. Canada; 2015.87 p. Ni43-I0I Technical Report. 
9 Associação Brasileira de Normas Técnicas -ABNT. ABNT NBR 14597: precisão de métodos analíticos: determinação da repetibilidade e reprodutibilidade de métodos para ensaios de produtos químicos. Rio de Janeiro; 2000.

I0 Instituto Nacional de Metrologia, Qualidade e Tecnologia - INMETRO. ABNT NBR ISO/IEC I7025:2005: requisitos gerais para competência de laboratórios de ensaio e calibração. Rio de Janeiro; 2005.

I I Instituto Nacional de Metrologia, Qualidade e Tecnologia - INMETRO. DOQ-CGCRE-008: orientação sobre métodos de validação analíticos. Rio de Janeiro; 2011 . 19 p.

I 2 Rivera C, Rodríguez R. Horwitz equation as quality benchmark in ISO/IEC I 7025 testing laboratory. In: 60 Annual Conference and Expo of the Institute of Industrial Engineers; 2010. Cancun; 2010. 5 v.

I 3 Belém J. Caracterização mineralógica, física e termobarométrica de minérios de grafita da província grafítica BahiaMinas [master's thesis]. Belo Horizonte: Instituto de Geociências, Universidade Federal de Minas Gerais; 2006.165 p.

I4 Magnesita Refratários S.A. Material fact: decisions of the board of directors concerning the mining project. São Paulo; 2014.

Received: 21 July 2016

Accepted: 29 Oct. 2016 